\title{
PERANCANGAN MEDIA INFORMASI SEBAGAI MEDIA PENUNJANG PENDIDIKAN KARAKTER SISWA SMP ISLAM AL MUSTARIH
}

\author{
Iis Purnengsih, Yayah Rukiah, Hamidah Apriani
}

Program Studi Desain Komunikasi Visual, Fakultas Bahasa dan Seni, Universitas Indraprasta PGRI

Jl. Nangka no.58c, Tanjung Barat, Jagakarsa, Jakarta Selatan, Indonesia

\begin{abstract}
Abstrak
Jika dilihat dari karakteristik psikologis usia siswa sekolah menengah pertama, pendidikan karakter menjadi sangat penting dalam upaya untuk membentuk karakter siswa SMP yang lebih beretika, bermoral, sopan santun dan berinteraksi dengan masyarakat. Pendidikan karakter akan berhasil bila disertai dengan media pembelajaran yang tepat. SMP Islam Al Mustarih adalah sekolah menengah pertama yang memiliki masalah yaitu belum memiliki sarana penunjang dalam pendidikan karakter siswanya. Kami tim dosen dari Universitas Indraprasta PGRI Jakarta memberikan solusi berupa pelatihan perancangan desain infografis dengan tema pendidikan karakter. Tujuan dari kegiatan pengabdian masyarakat ini adalah untuk memberikan pelatihan dan informasi yang menarik dalam bentuk poster dan sign system terkait Pendidikan Karakter. Metode penelitian yang digunakan adalah metode kualitatif yaitu dengan mengumpulkan data berupa survey ke lokasi mitra, wawancara dan pelatihan. Hasil dari penelitian ini adalah perancangan media informasi berupa poster dan sign system merupakan media yang efektif sebagai media penunjang dalam penyampaian pendidikan karakter untuk anak SMP.
\end{abstract}

Kata Kunci : Pendidikan Karakter, Poster, sign system

\begin{abstract}
When viewed from the psychological characteristics of the age of junior high school students, character education becomes very important in an effort to shape the character of junior high school students who are more ethical, moral, polite and interact with society. Character education will succeed if accompanied by the right learning media. Al Mustarih Islamic Middle School is a junior high school that has a problem that is not yet having the supporting facilities in the character education of its students. Our team of lecturers from Indraprasta University PGRI Jakarta provided solutions in the form of infographic design training and sign system with the theme of character education. The purpose of this community service activity is to provide interesting information in the form of posters and sign systems related to Character Education. The research method used is a qualitative method by collecting data in the form of surveys to partner locations, interviews and training. The conclusion of this study is that the design of information media in the form of posters and sign systems is an effective medium as a supporting media in the delivery of character education for junior high school children.
\end{abstract}

Keywords: Character Education, Poster, sign system

Correspondence author: Iis Purnengsih, iispurningsih@gmail.com, Jakarta, Indonesia

This work is licensed under a CC-BY-NC 


\section{PENDAHULUAN}

Pendidikan karakter merupakan pendidikan untuk membentuk kepribadian seseorang melalui pendidikan budi pekerti, yang hasilnya terlihat dalam tindakan nyata seseorang, yaitu tingkah laku yang baik, jujur, bertanggungjawab, menghormati hak orang lain, kerja keras dan lain sebagainya (Thomas Lickona, 1991). Selama ini pendidikan di dalam keluarga dinilai masih belum cukup memberikan kontribusi dalam mendukung pencapaian kompetensi dan pembentukan karakter peserta didik di sekolah.

Kesibukan dan aktivitas kerja orang tua yang relatif tinggi, kurangnya pemahaman orang tua dalam mendidik anak di lingkungan keluarga, pengaruh pergaulan di lingkungan sekitar, dan pengaruh media elektronik adalah faktor-faktor yang bisa berpengaruh negatif terhadap perkembangan dan pencapaian hasil belajar peserta didik.

Ilmu pengetahuan yang tinggi serta prestasi dalam belajar juga tidaklah cukup menjadikan seorang siswa memiliki sikap atau perilaku yang baik. Karena itu melalui pendidikan karakter diharapkan menjadi suatu sistem penanaman nilai-nilai karakter siswa sekolah yang meliputi komponen pengetahuan, kesadaran atau kemauan, dan tindakan untuk melaksanakan nilai-nilai tersebut, baik terhadap Tuhan Yang Maha Esa, diri sendiri, sesama, lingkungan, maupun kebangsaan.

Siswa sekolah menengah pertama adalah mereka yang usia nya berkisar antara 13 sampai dengan 15 tahun dan masuk pada kelompok masa remaja awal, seperti yang dijelaskan oleh Rumini \& Sundari (2004). Rumini dan Sundari menyatakan bahwa masa remaja adalah peralihan dari masa anak dengan masa dewasa yang mengalami perkembangan semua aspek/ fungsi untuk memasuki masa dewasa. Rentang waktu usia remaja ini biasanya dibedakan atas tiga, yaitu $12-15$ tahun = masa remaja awal, $15-$ 18 tahun = masa remaja pertengahan, dan $18-21$ tahun = masa remaja akhir.

Perkembangan psikologi dalam anggerrose.wordpress.com, terdapat beberapa karakteristik anak usia SMP antara lain :

1. Cara berfikir kausatif. Hal ini menyangkut tentang hubungan sebab akibat. Remaja sudah mulai berfikir kritis sehingga ia akan melawan bila orang tua, guru, lingkungan, masih menganggapnya sebagai anak kecil. Mereka tidak akan terima jika dilarang melakukan sesuatu oleh orang yang lebih tua tanpa diberikan penjelasan yang logis.

2. Perkembangan kognitif remaja, dalam pandangan Jean Piaget (seorang ahli perkembangan kognitif) merupakan periode terakhir dan tertinggi dalam tahap pertumbuhan operasi formal (period of formal operations). Berdasarkan pendapat Piaget tentang teori perkembangan kognitif, maka peserta didik usia SMP masuk pada kelompok tahap operasional formal (mulai 11 tahun dan seterusnya) dimana pada tahap ini peserta didik sudah mampu berpikir abstrak, yaitu berpikir mengenai ide dan memikirkan beberapa alternative pemecahan masalah remaja tidak lagi menerima informasi apa adanya, tetapi mereka akan memproses informasi itu serta mengadaptasikannya dengan pemikiran mereka sendiri (Haryanto, Suyono, 2014).

Terkait karakteristik psikologis siswa sekolah menengah pertama, pendidikan karakter menjadi sangat penting dalam upaya untuk membentuk karakter siswa yang beretika, bermoral, sopan santun dan berinteraksi dengan masyarakat.

Pendidikan karakter akan berhasil bila disertai dengan media penunjang dalam pembelajaran yang tepat. Dalam sistem pembelajaran, terdapat beberapa media yang dapat diterapkan untuk pendidikan karakter. Namun semua media yang digunakan harus bisa dikemas menarik, bisa berupa gambar atau ilustrasi yang menarik atau cerita yang 
menarik. Akan tetapi, kesemuanya berisi pesan terkait dan bermuatan pendidikan karakter, menjadi target penyampaian yang harus ditonjolkan. Pemilihan media juga harus disesuaikan dengan kondisi usia anak sekolah menengah pertama. Diperlukan kepekaan pendidik untuk memilih media tersebut.

Poster dan sign system adalah media-media yang cukup efektif digunakan sebagai sarana penunjang dalam penyampaian pendidikan karakter siswa di sekolah menengah pertama. Karena sebagai media cetak, poster dan sign system bersifat langsung (dapat dibaca langsung oleh pembacanya), efektifitasnya lebih rinci karena dalam penyampaian pesannya dapat berupa gambar dan tulisan, lebih mudah diingat atau didokumentasikan oleh pembacanya.

Berkaitan dengan pendidikan karakter anak usia sekolah menengah pertama, baik poster maupun sign system harus bisa dikemas atau didesain menarik agar anak-anak sekolah pertama tertarik untuk melihat dan membacanya. Pemilihan gambar atau ilustrasi, tipografi maupun warna harus bisa menyesuaikan karakter usia anak-anak sekolah menengah pertama sebagai audiens. Pesan yang disampaikan menggunakan bahasa yang lugas, mudah dibaca, mudah diingat dan mudah dipahami oleh audiens.

SMP Islam Al Mustarih adalah sekolah menengah pertama yang berdiri pada tahun 1978, terletak di Jl. Cibalagung No. III Pasir Kuda Bogor Barat. Jika dilihat dari situasi dan kondisi berdasarkan survei kami tim Pengabdian Masyarakat Universitas Indraprasta PGRI, terdapat dua permasalahan mitra yakni:

1. Belum memiliki sarana penunjang dalam menyampaikan informasi terkait pendidikan karakter siswa.

2. Belum memiliki sarana yang dapat menggugah dan mengarahkan perhatian siswa dalam meningkatkan pendidikan karakter.

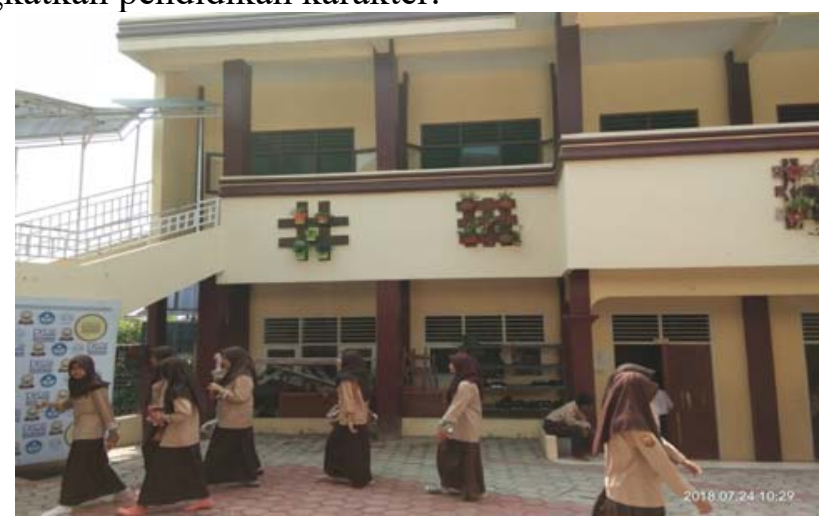

Gambar 1. Bagian depan SMP Islam Al Mustarih

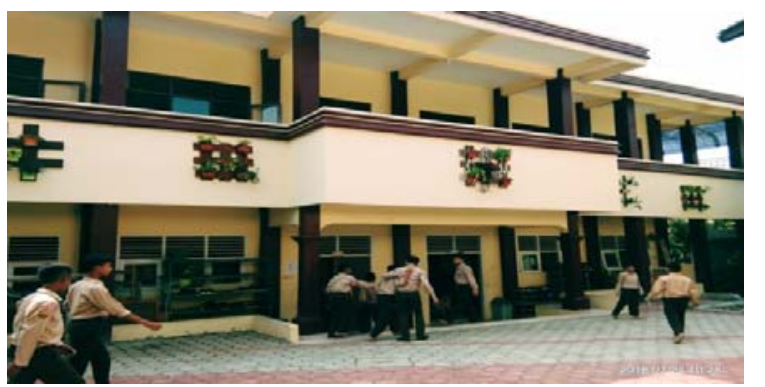

Gambar 2. Bagian tengah SMP Islam Al Mustarih 


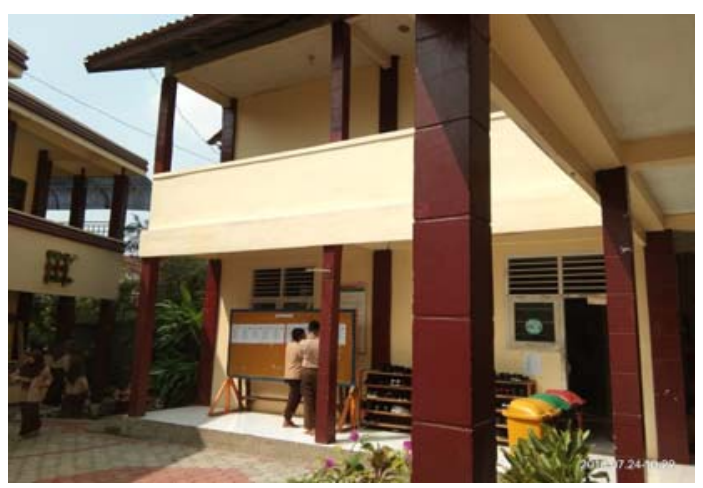

Gambar 3. Bagian Samping SMP Islam Al Mustarih

Sebagai bagian dari interaksi sosial dalam masyarakat dengan melihat permasalahan pada mitra. Kami Tim Pengabdian Masyarakat Universitas Indraprasta PGRI memberikan solusi berupa:

1. Pelatihan perancangan desain poster dan sign system sebagai sarana penunjang dalam menyampaikan informasi terkait pendidikan karakter.

2. Perancangan sign system sebagai sarana penunjang dalam upaya mengajak (persuasif) atau menumbuhkan sikap terkait pendidikan karakter.

Tujuan dari kegiatan abdimas adalah dengan adanya pelatihan dan penyampaian informasi yang menarik dalam bentuk poster dan sign system terkait Pendidikan Karakter. Hasil karya yang dihasilkan berupa 3 Poster dan 3 sign system. Dengan media informasi ini diharapkan mampu membentuk karakter siswa yang beretika, bermoral, sopan santun dan berinteraksi dengan masyarakat, serta siswa dan siswi SMP Islam Al Mutarik mampu membuat poster dan sign system dengan menggunakan komputer melalui pelatihan.

Manfaat kegiatan pengabdian masyarakat yang dilaksanakan di SMP Islam Al Mustarih adalah :

1. Memberikan informasi dalam bentuk poster dan sign system terkait Pendidikan Karakter.

2. Menambah pengetahuan siswa siswi tentang poster dan sign system.

3. Mampu mengoperasikan software dalam pembuatan desain poster dan sign system.

4. Melalui kegiatan abdimas ini dapat mereka aplikasikan selanjutnya di rumah mereka.

\section{METODE PELAKSANAAN}

Dengan pelatihan abdimas ini diharapkan poster dan sign system dapat dijadikan sebagai sarana penunjang pendidikan karakter di SMP Islam Al Mustarih. Target dalam arti sasaran pengabdian masyarakat adalah kurang lebih sepuluh siswa dan siswi SMP Islam Al Mustarih. Target dalam arti pencapaian yang dicanangkan dalam pengabdian masyarakat ini, bahwa setelah mengikuti kegiatan ini, diharapkan siswa dan siswi :

1. Dengan cara pelatihan langsung, dapat menggugah kesadaran pentingnya pendidikan karakter bagi siswa siswi SMP Islam Al Mustarih.

2. Siswa siswi jadi lebih kreatif.

Adapun luaran (output) Pengabdian Masyarakat ini adalah dalam bentuk 3 karya poster dan 3 sign system. Siswa sisiwi yang ikut pelatihan, yang akan kami 
dokumentasikan sebagai arsip lalu kami masukkan dalam laporan. Untuk publikasinya kami masukkan laporan kegiatan Pengabdian Masyarakat ini dalam bentuk Jurnal.

Proses pelaksanaan kegiatan Pengabdian kepada Masyarakat dilaksanakan selama 5 (lima) bulan, yaitu dimulai 15 September 2018 sampai dengan bulan Desember 2018. Pelaksanaan diawali dengan observasi dan wawancara di SMP Islam Al Mustarih, kemudian dilanjutkan dengan menyusun materi pelatihan. Dalam Kegiatan ini, metode pelaksanaan dibagi lima tahap :

1. Tim melakukan observasi dan wawancara untuk mengetahui apa yang dibutuhkan oleh mitra.

2. Hasil dari tahap observasi, kemudian dijadikan bahan pertimbangan untuk memberikan pelatihan yang belum pernah mitra lakukan.

3. Tahap selanjutnya kami mempersiapkan peralatan dan perlengkapan yang dibutuhkan.

4. Di dalam tahap pelatihan, diawal kami memberikan penjelasan mengenai pendidikan karakter, lalu menjelaskan tentang poster dan sign system, pelatihan membuat poster dan sign system dan terakhir pemasangan media pada tembok sekolah.

5. Pada pelatihan tersebut, para peserta mencoba mempraktikkan membuat poster dan sign system dengan mengikuti tahapan yang sudah dijelaskan. Hasil dari pelatihan ini di pasang di tembok sekolah dan mereka bisa mempraktekannya ilmu yang didapat di rumah masing-masing.

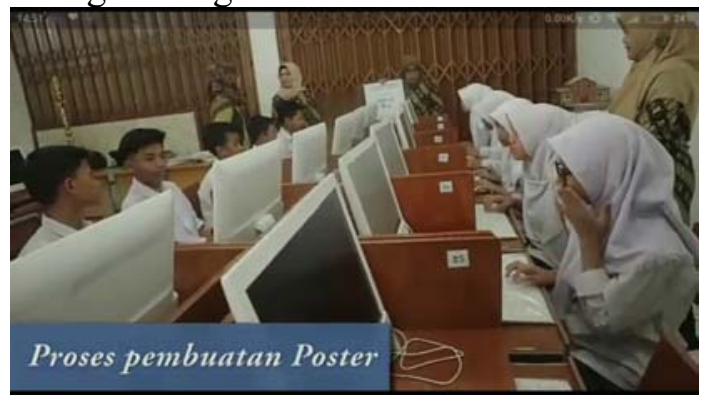

Gambar 4. Pelatihan membuat poster da sign system di Lab komputer

\section{HASIL PEMBAHASAN}

Pelatihan abdimas perancangan desain poster dan sign system diawali memberikan penjelasan tentang pendidikan karakter dan media informasi berupa poster dan sign system kepada siswa siswi SMP Islam Al Mustarih serta teknik membuat poster dan sign system pada komputer. Untuk pelatihan ini siswa siswi diberikan alternatif dalam penggunaan software yang mudah dipahami yaitu photo paint, agar peserta dapat terus mempraktikkan ilmu yang diberikan dari pelatihan ini.

Langkah-langkah dan teknis abdimas pembuatan poster dan sign system yaitu :

1. Menjelaskan software yang digunakan yaitu photo paint, yaitu program khusus untuk membuat gambar di komputer. Software photo paint ringan digunakan anakanak SMP dan mudah dipahami. Namun disayangkan pada saat praktik latihan membuat desain, tidak semua komputer di SMP tersebut ada software photo paint. Jadi sebelum pelatihan dimulai kami tim abdimas meng install program photo paint di komputer-komputer SMP Islam Al Mustarih. 


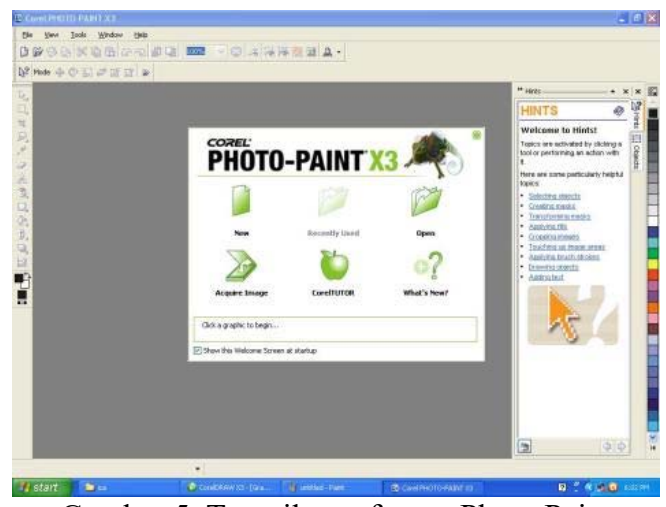

Gambar 5. Tampilan software Photo Paint

2. Membuat konsep desain yaitu berupa sketsa pemilihan gambar atau ilustrasi, tipografi maupun warna disesuaikan dengan karakter usia anak-anak sekolah menengah pertama sebagai audiens. Pesan yang disampaikan menggunakan bahasa yang lugas, mudah dibaca, mudah diingat dan mudah dipahami oleh audiens.

3. Menjelaskan fitur-fitur yang ada di photo paint

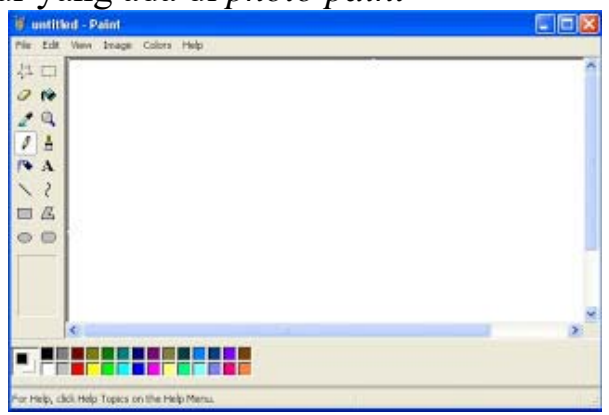

Gambar 6. Fitur-fitur dalam Photo Paint

4. Hasil desain yang menarik dipilih untuk dicetak

5 NILAI UTAMA PENGUATAN

PENDIDIKAN KARAKTER
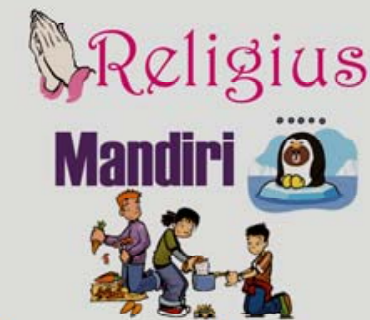

Gofong Royong

Es Integritas

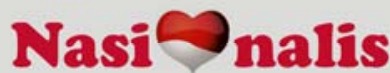

Kelima nilai utama karakter bukanlah nilai yang berdiri dan berkemban sendiri-sendiri melainkan nilai yang berinteraksi satu sama lain, yang
berkembang secara dinamis dan membentuk keutuhan pribadi

Gambar 7. Salah satu hasil pelatihan 
5. Terdapat 3 desain poster dan 3 desain sign system yang menarik untuk di pasang ditembok sekolah

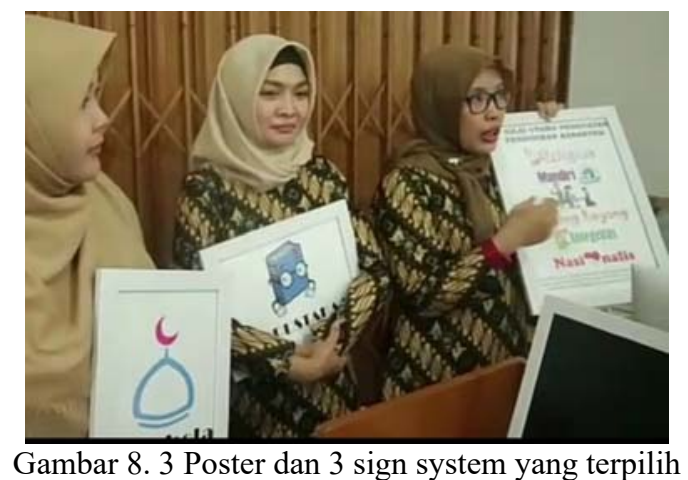

6. Apresiasi karya dengan kepala sekolah, guru-guru dan siswa siswi SMP Islam Al Mustarih.

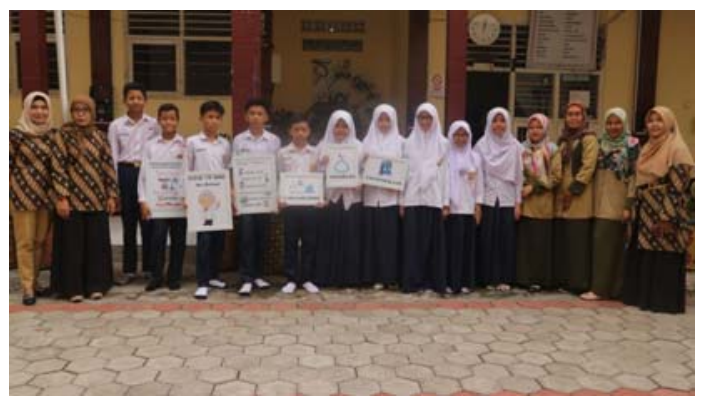

Gambar 9. Foto bersama tim abdimas dan mitra

Penyuluhan dan pelatihan berjalan dengan baik. Siswa siswi SMP Islam Al Mustarih sangat antusias memperhatikan dan mencoba praktik langsung atas apa yang sudah kami contohkan dalam pelatihan ini. Dalam praktik langsung membuat desain poster dan sign system semua sudah berjalan dengan lancar, namun tingkat kesabaran dan ketelitian siswa siswi yang berbeda menjadikan hasil yang mereka dapatkan ada yang bagus ada yang kurang bagus. Hasil praktik langsung peserta yang bagus dalam membuat desain poster dan sign system kami persilahkan untuk dipasang di tembok sekolah SMP Islam Al Mustarih dan kami berikan sebagai kenangan dari kami.

\section{SIMPULAN}

Pendidikan karakter akan berhasil bila disertai dengan media pembelajaran yang tepat. Solusi berupa pelatihan perancangan desain infografis dan sign system dengan tema pendidikan karakter merupakan salah satu cara yang tepat dalam penyampaian pendidikan karakter bagi anak-anak usia remaja. Karena itu poster dan sign system merupakan media yang efektif sebagai media penunjang dalam penyampaian pendidikan karakter untuk anak SMP.

\section{DAFTAR PUSTAKA}

Doni, A. Koesoema (2007), Tiga Matra Pendidikan Karakter, Basis

Erlina \& Kesuma, I.M. A. (2013). Membuat Media Mengajar Visual. Jakarta : Erlangga 
Rustan, S. (2010). Layout dasar dan Penerapannya. Jakarta : gramedia Pustaka Utama.

Soetjiningsih, C.H (2012). Perkembangan Anak : Sejak Pembuahan Sampai Dengan Kanak-kanan Akhir : Prenada

Suproyono. R. (2010). Desain Komunikasi Visual Teori dan Aplikasi. Yogyakarta : Andi

Sugiyono. (2014). Memahami Penelitian Kualitatif, bandung : Vc Alfabeta

Suwati. (2008). Sekolah Bukan Sekedar Mencari Pekerjaan. Jakarta Grafia.

https://www.lyceum.id/pengertian-tujuan-dan-fungsi-pendidikan-karakter/ 